Vol 13, Issue 9, 2020

\title{
A INCIDENCE, PREVALENCE, AND CLINICAL MANAGEMENT OF POISONING CASES IN TELANGANA STATE REGION - A PROSPECTIVE STUDY
}

\author{
POTHULA HARISHWARREDDY*, NAGALATHA D, VEENA G
}

Department Pharmacy Practice, Sri Indu Institute of Pharmacy, Ranga Reddy, Telangana, India. Email: pothulaharishwarreddy@gmail.com Received: 12 May 2020, Revised and Accepted: 23 June 2020

\begin{abstract}
Objectives: This study aimed to find the incidence, prevalence, and clinical management of poisoning cases in Telangana state region.

Methods: It was a prospective and observational study done for 9 months and the data were obtained from the case sheets of 600 patients admitted in tertiary care hospital with poisoning. Data were analyzed according to age, gender, type and route of poisoning, treatment of poisoning, and mortality and morbidity rate.
\end{abstract}

Results: Out of 600 cases admitted, female patients were 312 (52\%) and males were 288 (48\%) and the age group ranged from 6 months to 70 years of age. The most common route of exposure was ingestion (oral) (91.5\%) followed by topical (dermal) (8\%), and the agents which were used included organophosphate (33\%) in most of the cases followed by chemical poisoning (24\%). The average duration of therapy till the discharge of the patients was 1-5 day. About $80 \%$ of the cases were from the low socioeconomic background. More or less, the treatment is restricted to symptomatic and supportive care if the poisonous agent is unknown. A specific antidote is given, where there is enough information regarding the poison.

Conclusion: The present study revealed increasing incidence of poisoning cases from rural areas and below the poverty line due to lack of knowledge, easy availability, stress, depression, and familial disharmony. By providing educational, awareness programs, and establishing a poison information center, there is a possibility for a decline in the incidence of poisoning.

Keywords: Poisoning, Mortality, Morbidity, Intentional, Antidote.

(c) 2020 The Authors. Published by Innovare Academic Sciences Pvt Ltd. This is an open access article under the CC BY license (http://creativecommons. org/licenses/by/4. 0/) DOI: http://dx.doi.org/10.22159/ajpcr.2020.v13i9.38263

\section{INTRODUCTION}

A poison is any substance that is harmful to your body when ingested, inhaled, or absorbed through the skin. Poisons have been used for many purposes across the span of human existence, most commonly as weapons, anti-venom, and medicine [1]. Illness may occur very quickly soon after exposure to a poison, or it may develop over several years with long-term exposure. According to the WHO (World Health Organization) estimate published in 1990 (World Health Organization 1990), around 3 million poisoning cases with 2,20,000 death occur annually. About $99 \%$ of this death occur in developed countries [2].

Over the last few decades, agricultural pesticides have become a common household item in rural areas of the developing world due to their easy availability. In addition to this, household substances such as insecticide, rodenticide, mosquito repellent, kerosene, hair oil, and medicine are also used for intentional poisoning, due to effortless availability, lack of knowledge, stress in academic, financial status, social sectors, and familial disharmony. However, the morbidity and mortality of poisoning cases differ from country to country. All the documented cases of poisoning are either recorded as unnatural death with a medicolegal autopsy, as per the legal system of our country.

Assessment and appropriate treatment of poisoning is based on precise evaluation and timely therapy. Most of the poisoning patients are treated with supportive care. Only in few cases, different types of specific antidotes are used according to the type of poisoning administered by the patient. The probabilities for enhanced outcomes occur with early diagnosis and management. Therefore, the present study was carried out to assess the incidence, prevalence, and clinical management of poisoning cases in a tertiary care hospital of Telangana region.

\section{MATERIALS AND METHODS}

\section{Methodology}

The major objective of the study was to identify the incidence and prevalence of poisoning cases admitted in the tertiary care hospital and their clinical management with special preference to nature and route of poisoning, intentional and unintentional rate of poisoning, and mortality and morbidity rate.

\section{Study design}

It is a prospective and observational study to determine the incidence, prevalence, and clinical management of poisoning cases in Telangana region. The study was carried out in various tertiary care hospitals located in Hyderabad premises. It was conducted for 9 months, that is, from June 2019 to February 2020. All the studies were approved by the Institutional Ethics Committee.

\section{Study criteria}

Patients who were admitted in the emergency care department with a cause of poisoning were included in the study. The criteria were from $>6$ month of age along with these all types of poisoning, medicolegal cases, and poisoning patient of known and unknown origin, which were included in this study. Children below 6 months of age, pregnant women, other than medicolegal cases, ingestion of non-digestible substances like coins, pins, and plastic were excluded from the study. Along with these sexual assaults, criminal abortions and deliberate selfharm such as hanging, self-inflicted wounds, and cuts are excluded from the study.

\section{Data collection}

The demographic details of the patient, drugs prescribed, and information regarding the use and cause of poisoning were collected in a prepared prescribed format. All the relevant and necessary data 
were collected from (a) patient case profile, (b) treatment chart, (c) interviewing with healthcare professionals, and (d) interacting with the patients or their caretakers at the bedside (family and friends) any other relevant sources.

\section{Study procedure}

All the patients admitted during the study period (9 months) from inpatient were reviewed prospectively on a daily basis by the clinical pharmacist. The patient who met the study criteria were included in the study. Data of those patients were collected and documented. All the enrolled patients were monitored intensively from day to day until the day of discharge and change to drug therapy, if any was noted on a daily basis were documented. The final obtained data were analyzed, and results were formulated.

\section{Data analysis}

The collected data were evaluated using descriptive statistics, and the results were represented as percentage data.

\section{RESULTS}

A prospective and observational study was conducted to investigate the incidence, prevalence, and clinical management of poisoning cases in Telangana region. Results were analyzed from the data obtained during the study under the following parameters age, gender, type and route of poisoning, treatment plan, intentional, unintentional, mortality and morbidity, etc. Out of 600 cases, male patients were $288(48 \%)$ and female patients were $312(52 \%)$, and their ratio will be 12:13.

Most of the cases belong to age group 21-30 years (40\%) followed by $31-40$ years $(19.5 \%), 11-20$ years (19\%), 40-50 years (11.5\%), 51-60 years (5\%), $0-10$ years ( $4.5 \%)$, and $61-70$ years $(0.5 \%)$. Pediatric cases above 6 months of age also included in the study, and their results were $4.5 \%$ between the age of 6 months and 10 years and geriatric patients were about $0.5 \%$.

In our study youngest, the patient was 6 months of age while the oldest patient was 70 years old. Among various routes of exposure to poison. Ingestion was the most common route of exposure $(91.5 \%)$ followed by dermal ( in case of bites) (8\%) and inhalation (0.5\%).

Out of 600 cases, 33\% (198) cases were due to OP compound ingestion followed by chemical poisoning 24\% (144), drug overdose 19\% (114), corrosive poisoning $12 \%$ (72), snakebite $8 \%$ (48), and unknown compound ingestion $4 \%(24)$.

This is mainly due to the easy availability of pesticides for farmers, depression, mental torture, and familial disharmony due to external affairs of husband and infertility in the case of females. The adults are more prone to poisoning due to stress in academic, financial and social sectors, as well as the inability to achieve the target on professional, educational, and socio economic status. Unintentional poisoning is most commonly seen in pediatrics and rarely in adults during spraying of pesticides or use of inhalers, especially in case of asthma, chronic obstructive pulmonary disease, epilepsy, etc.

Most of the above poison patients were treated with supportive care (423), only a limited no of patients was treated with a specific antidote (117).

Primarily gastric lavage (549) was done for almost all the patients consumed the poison through an oral route which is followed by antidote (117) and supportive care (423) (symptomatic treatment) was provided to the patients.

Among antidotes used to treat the above poison patients, the most commonly used antidote were atropine (110), pralidoxime (PAM) (42), and anti-snake venom (40). Only in few patients, both types of antidotes were used, namely, atropine and PAM (15 cases $=2.5 \%)$.
Out of 600 patients were admitted in the hospital with different types of poisoning about $56.6 \%$ (340) of the patients were discharged in 1-5 days followed by $26.6 \%$ (160) of patients that were discharged in 5-10 days, remaining $6.6 \%$ (40) of patients were discharged in 10-15 days. However, few people are prone to death $10 \%$ (60) within the first 5 day during the hospital stay.

Out of 600 cases reported to tertiary care hospital with poisoning, only about $10 \%$ (60) patients were prone to death, remaining 90\% (540) patients were recovered with the treatment provided to the patients by the hospital doctors and staff as well.

Suicidal poisoning was about $94 \%$ (564) and only 6\% (36 cases) are due to unintentional poisoning. Most of the unintentional poisoning were seen in pediatrics, followed by farmers while spraying pesticides and the patients using inhalers for respiratory and other diseases.

The cases reported that tertiary care hospital with poisoning was analyzed according to a geographical area so that our study reveals that the patients belong to Hyderabad district, which are more prone to poisoning followed by Rangareddy, Siddipet, Yadadri, Medchal (malkajgiri), Medak, Mahabubnager, Nagerkurnool, Vikarabad, Karimnager, Khammam, Sangareddy, Warangal, Mahabubabad , Kamareddy , Jayashanker, etc., exposing to poisoning.

\section{DISCUSSION}

In developed countries, the mortality rate from poisoning is identified to be $1-2 \%$, which is comparatively less in developed countries like India, where more than 50,000 deaths occur due to toxic exposure [3]. Data from the previous studies in India have provided information regarding the direct association of demographic factors with outcomes. Even through previous studies had described the socio-demographic profile of the poisoning victims. In this study, we aimed to assess incidence, prevalence, and clinical management of poisoning in Telangana region. There are a number of aspects, on which the outcome of poisoning treatment depends on type of poison consumed, quantity of poison, availability of healthcare facilities and services, and time interval

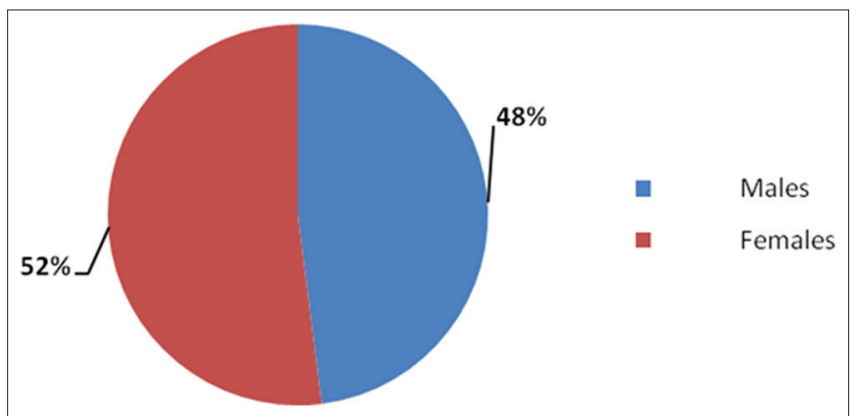

Fig. 1 : Number of males and females prone to poisoning

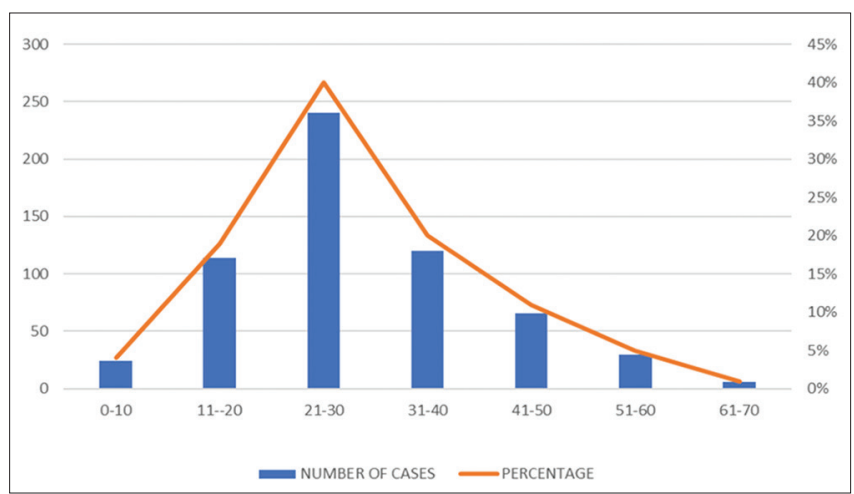

Fig. 2: Number of poisoning cases by age 


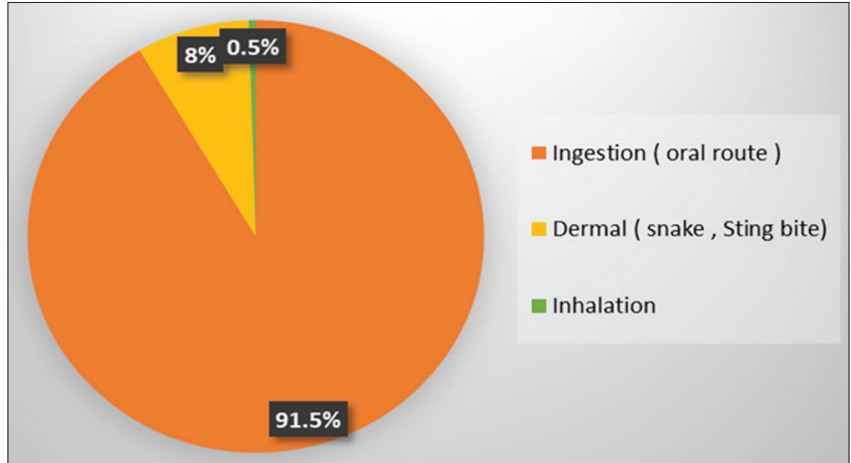

Fig. 3: Route of poisoning

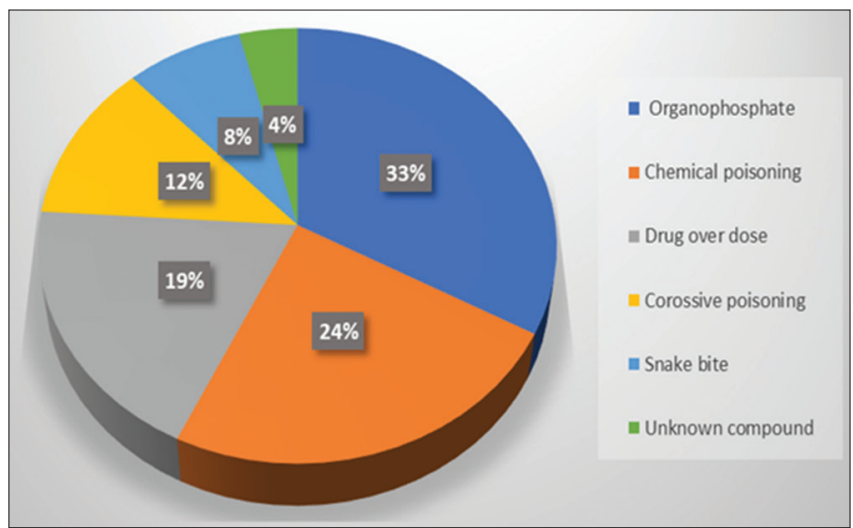

Fig. 4: Type of poisoning

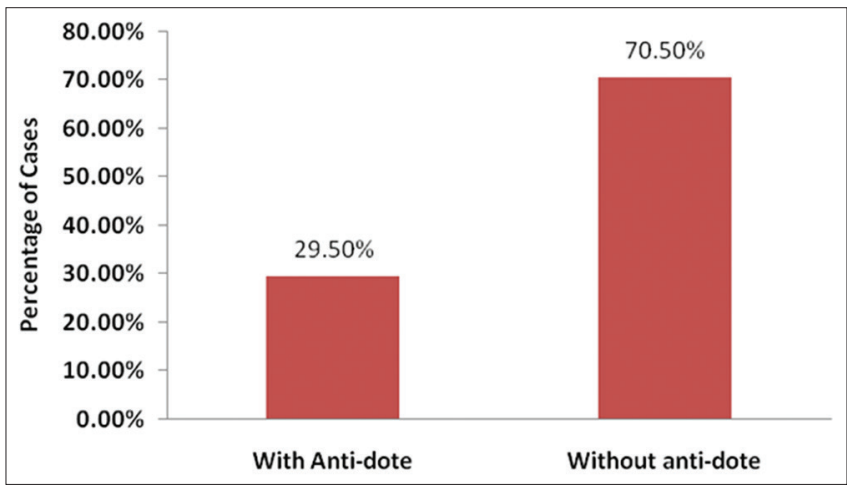

Fig. 5: Treatment plan for poisoning

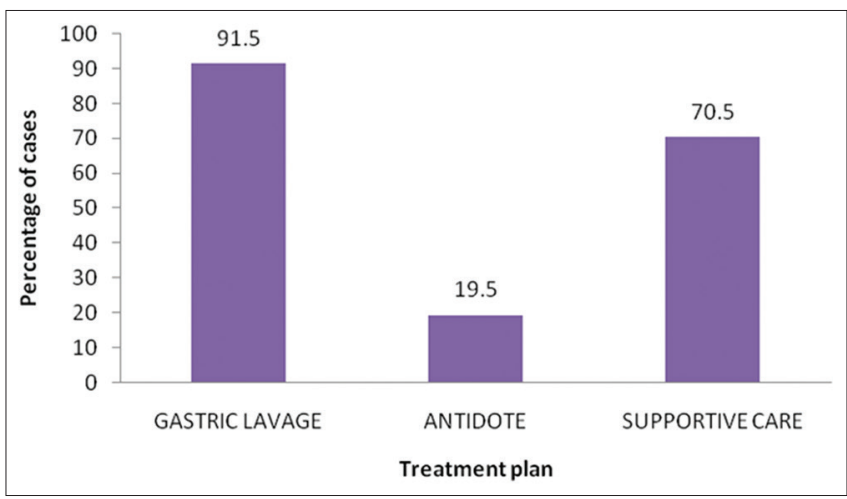

Fig. 6: Treatment plan for poisoning

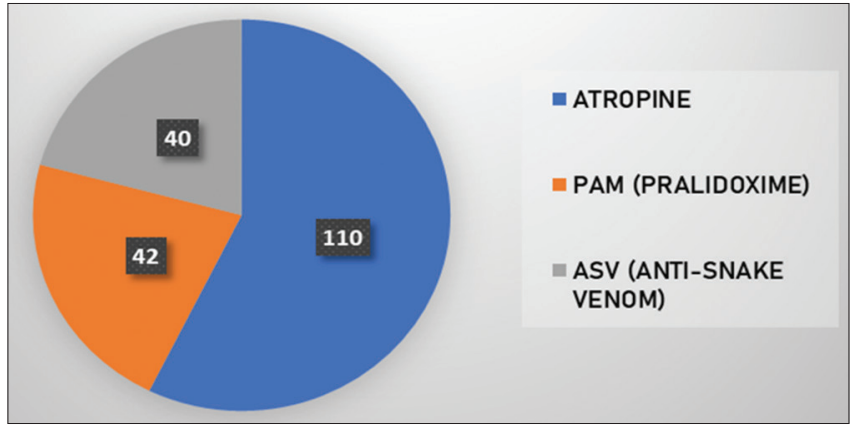

Fig. 7: Type of antidote used to treat poisoning

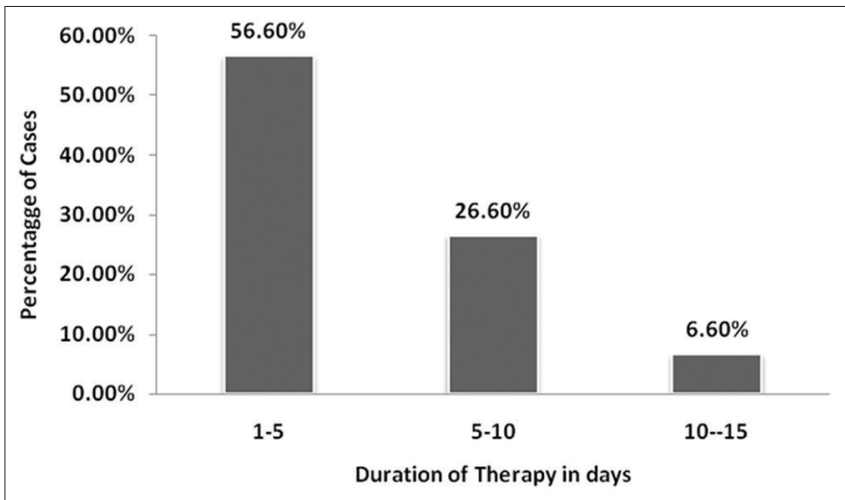

Fig. 8: Duration of treatment

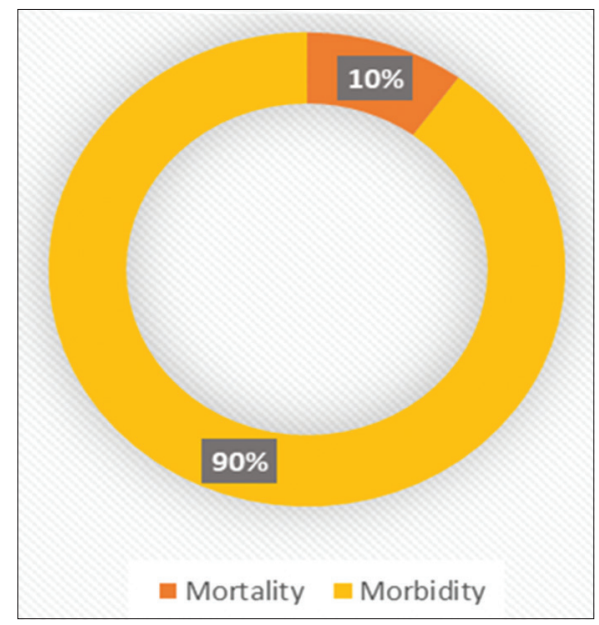

Fig. 9: Mortality and morbidity rate of poisoning

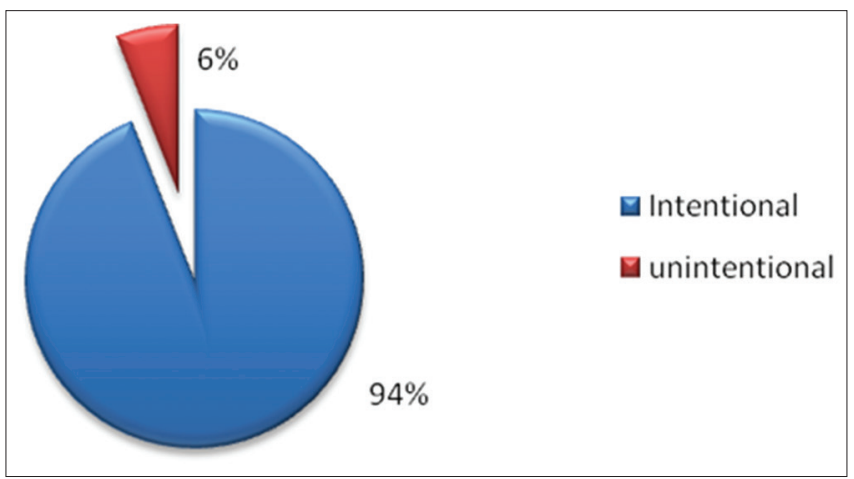

Fig. 10: Intentional and unintentional rate of poisoning 


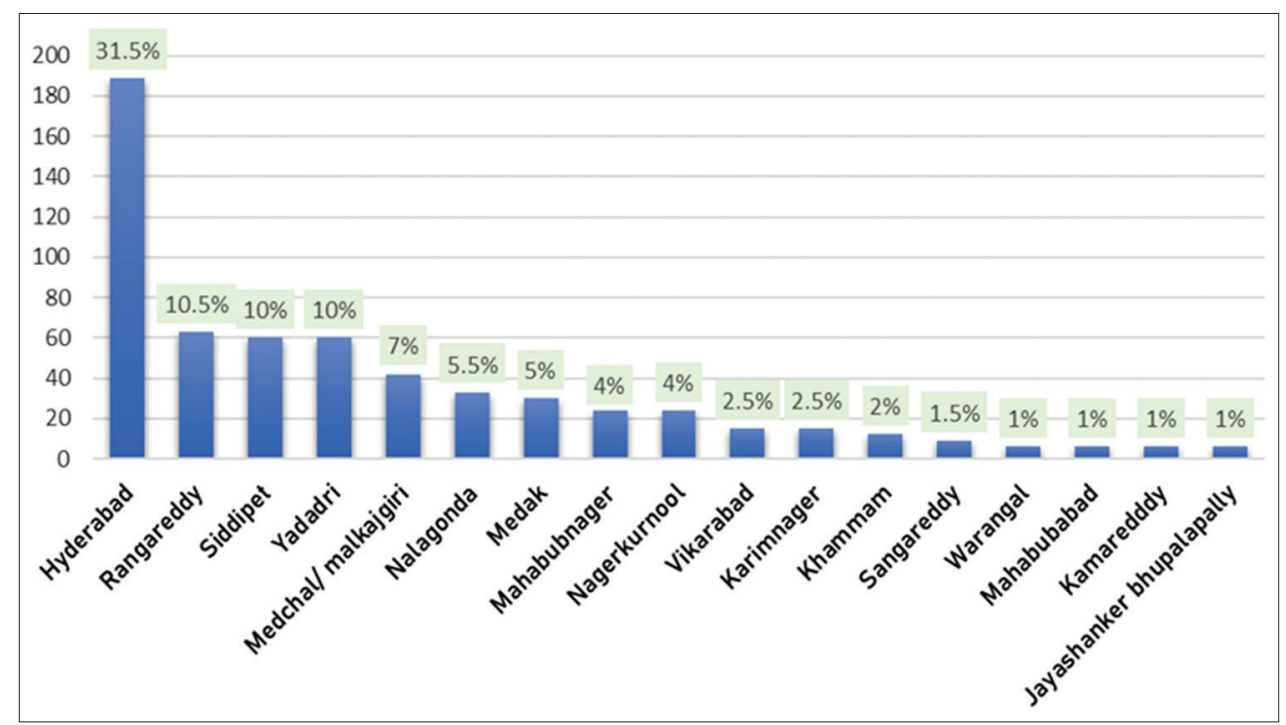

Fig. 11: Number of case presenting to the hospital according to a geographical area

between ingestion of poison treatment initiation and appropriate measures used for the treatment [4]. The results of the outcome can improve if patients were bought immediately to the hospital and appropriate management is done.

The result of our study showed that poisoning was more common in female $(52 \%)$ as compared to that in male $(48 \%)$. This finding is supported by other studies done in different countries [5-7]. This might be due to an increase burden of factors among females that contribute to committing suicide in the male dominant society in underdeveloped and developing countries. The factors could be depression, mental torture, and familial disharmony due to external affairs of husband and infertility. While in some studies, either there was an equal distribution of poisoning among gender or poisoning was common in male [8-11]. Likewise, in our study, insecticide poisoning (33\%) was common, which was supported by other studies $[12,13]$. This result might be due to the easy availability of insecticides in the market in our agriculturebased countries. Furthermore, improper storage of chemicals at home can make an easy approach towards them during the impulsive act on poisoning. Contrary to the finding our result, some studies showed that drug and household cleansing agents were a common form of poisoning [6-9]. The majority of the patients in our study are $423(70.5 \%)$ that were managed by general or supportive measures. Specific antidotes were administered in about 177 (29.5\%) patients with poisoning. The proper treatment with antidote may remarkably neutralize the toxic action of the poison and increase its elimination. Our findings were similar to other studies conducted [13-16] Atropine and PAM were commonly administered by parenteral routes in those patients among insecticide poisoning consumed the organophosphorus compound. Hence, atropine competitively antagonizes muscarinic effects of those compounds and PAM reactivates cholinesterase enzyme. Glycopyrrolate is another anticholinergic drug that can be used for the treatment of organophosphorus poisoning [17]. In addition to this other drugs like anti-ulcer drugs, especially proton pump inhibitors and H2-receptor blocker to prevent gastric erosion and to reduce excess gastric acid secretions [18]. In addition, psychological consultations were also done in most of the suicidal cases. Suicidal ideation and behaviors are important markers for suicidal attempts. They are associated with many risk factors such as financial loss and sense of isolation from society. Furthermore, major depression is a significant psychiatric disorder which is associated with suicidal attempts in all age group. Thus, a psychological evaluation is necessary in all cases of suicidal attempts so that the patient can be treated accordingly and future repeated suicidal attempts can be prevented. Moreover, the present study demonstrated that most of the patients improved after treatment, and mortality (10\%) was low. Other studies also agreed with our findings, where total mortality was low [16,19-21]. The mortality in other patients might be due to various factors like delay in arrival to hospital and lack of information related to type and dose of poison consumed.

The noticeable point of our study is that the majority of patients admitted improved after appropriate treatment provided by the hospital management. The reason behind this is due to high quality of healthcare providers and healthcare facilities, ingestion of low dose of poison, and early discovery of ingestion of poison by family members or friends.

Finally, we feel that there is a need for studies that aim to find out the causes of suicidal poisoning in society. Educational and awareness programs, establishment of poison information and surveillance centers, and regulations on pesticides/drug availability will form one of the important strategies for the prevention of emergencies.

\section{CONCLUSION}

Poisoning is the most common cause of death in underdeveloped and developing countries. Pesticides poison is the most common cause of suicidal poisoning in addition to these other household substances such as insecticide, rodenticide, mosquito repellent, corrosive poison, hair dye, and kerosene. These are mainly used for poisoning due to their easy availability, lack of knowledge, depression, stress from academic, and financial. According to our study by providing educational and awareness programs, the establishment of poison information and surveillance centers and regulations on pesticides/drug availability and their proper storage leads to decrease in the incidence of poisoning.

\section{AUTHORS' CONTRIBUTIONS}

Conception or design of the work : Pothula Harishwarreddy, D. Naga Latha and G. Veena.

Data collection: Pothula Harishwarreddy

Data analysis and interpretation: Pothula Harishwarreddy, D. Naga Latha and G. Veena.

Drafting the article: Pothula Harishwarreddy

Critical revision of the article: Pothula Harishwarreddy, D. Naga Latha and G. Veena. 
Final approval of the version to be published: Pothula Harishwarreddy, D. Naga Latha and G. Veena.

\section{AUTHORS' FUNDING}

The work is not supported by any funding agency.

\section{CONFLICTS OF INTEREST}

The authors declare that there are no conflicts of interest to report.

\section{REFERENCES}

1. Khosya S, Meena SR. Current trends of poisoning: An experience at a tertiary care hospital Hadoti region, Rajasthan, India. J Clin Toxicol 2016;6:2.

2. World Health Organization. Public Health Impact of Pesticides Used in Agriculture. Geneva: World Health Organization; 1990.

3. Reddy S, Revathi D, Prasanna VL, Ramesh AC. Sociodemographic profile of patient with acute poisoning in the emergency wards of a teritary care hospital. Int J Pharm Pharm Sci 2018;10:50-6.

4. International Programme on Chemical Safety World Health Organization. Poisoning Prevention and Management. Geneva: International Programme on Chemical Safety World Health Organization; 2014. Available from: ???. [Last accessed on 2017 Jun 22].

5. Adinew GM, Woredekal AT, DeVos EL, Birru EM, Abdulwahib MB. Poisoning cases and their management in emergency centers of government hospitals in northwest Ethiopia. Afr J Emerg Med 2017;7:74-8.

6. Wakushie J, Fekede BD. Pattern of acute poisoning and management outcome among patients presented to Adama referral hospital, Ethiopia. Med Data 2016;8:185-9.

7. Nair PK, Revi NG. One-year study on pattern of acute pharmaceutical and chemical poisoning cases admitted to a tertiary care hospital in Thrissur, India. Asia Pac J Med Toxicol 2015;4:79-82

8. Patil A, Peddawad R, Verma VC, Gandhi H. Profile of acute poisoning cases treated in a tertiary care hospital: A study in Navi Mumbai. Asia Pac J Med Toxicol 2014;3:36-40.
9. Aravinda V, Bedwal A, Rajarathna K, Swamy MN. Pattern and pharmacotherapy of acute poisonings presenting to a tertiary care centre. Int J Basic Clin Pharmacol 2017;6:879.

10. Chen F, Wen JP, Wang XP, Lin QM, Lin CJ. Epidemiology and characteristics of acute poisoning treated at an emergency center. World J Emerg Med 2010;1:154-6.

11. Mbarouk GS, Sawe HR, Mfinanga JA, Stein J, Levin S, Mwafongo V, et al. Patients with acute poisoning presenting to an urban emergency department of a tertiary hospital in Tanzania. BMC Res Notes 2017;10:482.

12. Kishore PV, Palaian S, Paudel R, Mishra D, Ojha P, Alam K, et al. Pattern of poisoning cases in a teaching hospital in Western Nepal. J Inst Med 2008;30:26-34

13. Shanmugam S, Wilson NA. Study on management of various poisoning cases at a tertiary care teaching hospital. Int J Pharmacol Toxicol 2016;4:220-3.

14. Shakya RP, Adhikary S, Bajracharya R. Pattern of acute poisoning attending a tertiary care hospital of Western Nepal. J Lumbini Med Coll 2016;4:90.

15. Maheswari E, Abraham L, Chacko C, Saraswathy G, Ramesh A. Assessment of pattern, severity and outcome of poisoning in emergency care unit. J Appl Pharm Sci 2016;6:178-83.

16. Asari PD, Shah SM, Amin AJ, Patel ND. Drug utilization study on acute poisoning cases treated at a tertiary care hospital in Western part of India. Asia Pac J Med Toxicol 2016;5:20-4.

17. Kulkarni M, Patil A. Characteristics of patients with organophosphorus poisoning and its management: Pharmacoepidemiological evaluation. Asian J Pharm Clin Res 2019;12:86-8.

18. Sasidharan P. A retrospective study on drug utilization pattern of poisoning cases admitted in a teritary care teaching hospital. Asian J Pharm Clin Res 2020;13:67-72.

19. Z'gambo J, Siulapwa Y, Michelo C. Pattern of acute poisoning at two urban referral hospitals in Lusaka, Zambia. BMC Emerg Med 2016;16:2-8.

20. Acharya S, Lakshminarayana K, Sharanappa M. Assessment of poisoning cases in a tertiary care hospital. Int J Biomed Res 2014;5:578-81.

21. Paudyal BP. Poisoning: Pattern and profile of admitted cases in a hospital in central Nepal. JNMA J Nepal Med Assoc 2005;44:92-6. 